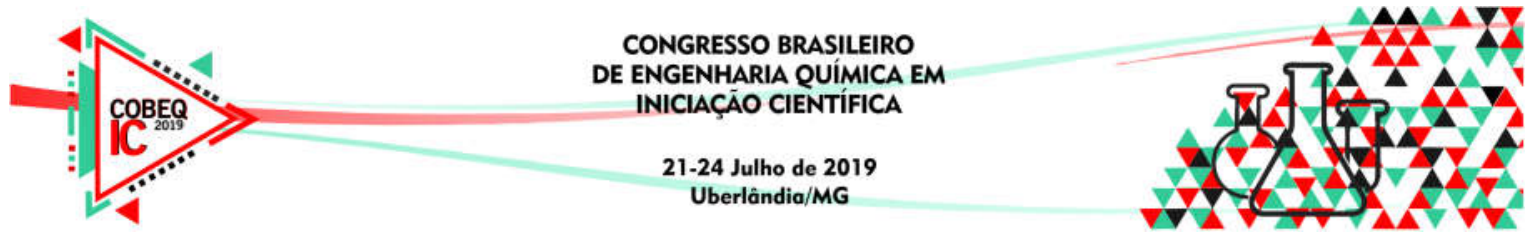

\title{
INVESTIGAÇÃO PRELIMINAR DO PREPARO DE PELLETS CILÍNDRICOS DE PENTÓXIDO DE NIÓBIO VIA EXTRUSÃO PARA USO EM REAÇÕES COM DERIVADOS DA BIOMASSA LIGNOCELULÓSICA
}

\author{
G. G. DE ALBUQUERQUE ${ }^{1}$, D. S. S. JORQUEIRA ${ }^{1}$ e R. S. SUPPINO ${ }^{1}$ \\ ${ }^{1}$ Universidade Estadual de Campinas, Faculdade de Engenharia Química \\ E-mail para contato: suppino@unicamp.br
}

\begin{abstract}
RESUMO - A catálise heterogênea vem ganhando espaço em processos químicos, com destaque para os processos em biorrefinarias que utilizam diversas fontes renováveis para produção de insumos químicos. Entre os catalisadores mais promissores para reações de desidratação encontra-se o pentóxido de nióbio $\left(\mathrm{Nb}_{2} \mathrm{O}_{5}\right)$. Boa parte dos testes catalíticos são realizados atualmente com catalisadores em pó devido a possibilidade de redução dos efeitos de transferência de massa. No entanto, o desenvolvimento de catalisadores em forma de pellets se faz necessário para um aumento de escala e no caso de operação em reatores contínuos. No presente estudo foram produzidos pellets de pentóxido de nióbio via extrusão utilizando álcool polivinílico (PVA) como agente aglomerante num teor mássico de $10 \%$ e $15 \%$, visando a futura aplicação em reações com materiais derivados da biomassa lignocelulósica. Após tratamento térmico em estufa durante $24 \mathrm{~h}\left(\mathrm{a} 70^{\circ} \mathrm{C}, 120^{\circ} \mathrm{C}\right.$ e $\left.200{ }^{\circ} \mathrm{C}\right)$, os pellets tiveram sua coloração alterada de branco para marrom, porém as estruturas contendo 10\% de PVA apresentaram resistência mecânica frágil, rompendo durante seu resfriamento. Desse modo, este estudo serve como ponto de partida para desenvolvimento de novas formulações de pellets a partir dos resultados iniciais apresentados.
\end{abstract}

\section{INTRODUÇÃO}

Atualmente, tem-se estudado o desenvolvimento de combustíveis e produtos químicos em processos menos agressivos como alternativa aos produtos de origem fóssil. Oscilações no preço do petróleo, diminuição esperada dessa fonte energética e o aumento das emissões dos gases causadores do efeito estufa são considerados os principais problemas da dependência dessa fonte energética (Alonso et al., 2010; Mariscal et al., 2016). Entre as fontes de energia renovável, a biomassa é a mais abundante e representa cerca de $9 \%$ da oferta total de energia primária do mundo (Pradhan et al., 2018). Nesse sentido, a transformação da biomassa lignocelulósica em commodities da indústria química tem sido considerada uma das tecnologias mais promissoras deste século. Além disso, o número de rotas para a transformação de biomassa em produtos químicos é muito abrangente.

Dentre os diversos modos de obtenção de produtos a partir da biomassa lignocelulósica, destaca-se a catálise heterogênea, que tem como principal vantagem a facilidade de separação entre catalisador e meio reacional. Os catalisadores heterogêneos empregados podem ser 


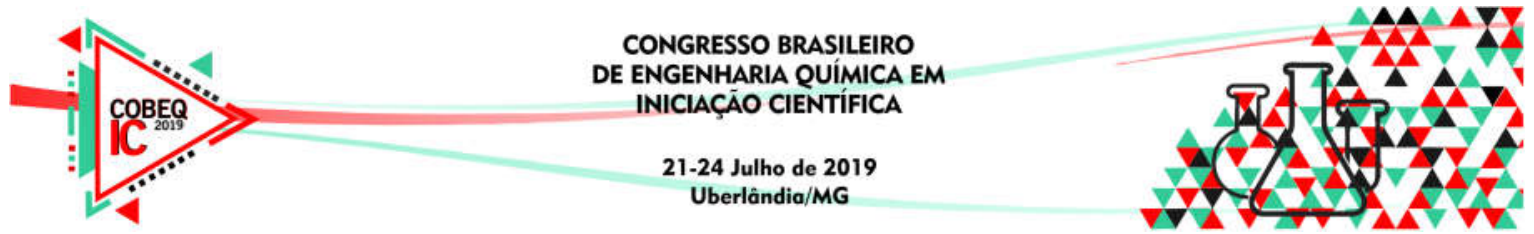

zeólitas, sílicas, catalisadores metálicos e também óxidos (Mariscal et al., 2016). Em muitas reações com açúcares (pentoses e hexoses), se faz necessário que o catalisador apresente sítios ácidos em sua estrutura, para promover a desidratação destas moléculas. Assim, o pentóxido de nióbio $\left(\mathrm{Nb}_{2} \mathrm{O}_{5}\right)$ é um catalisador que apresenta acidez e que está sendo amplamente estudado para a produção de diversas moléculas como furfural, e em reações de transesterificação, esterificação e pirólise de óleos vegetais, segundo Mariscal et al. (2016). Além disso, o que torna o estudo desse óxido ainda mais vantajoso é que o Brasil possuí uma parcela considerável das reservas de nióbio do planeta (Alves e Coutinho, 2015).

Ressalta-se, no entanto, que boa parte dos testes catalíticos é realizado atualmente em batelada e com catalisadores em pó, com o intuito de reduzir as limitações por transferência de calor e de massa (García-Sancho et al., 2014; Canhaci et al., 2017). Em escala de bancada, o catalisador em pó dificulta uma operação de um conversor contínuo devido à maior queda de pressão no reator, sendo esse mesmo fenômeno verificado no aumento de escala (De Jong, 2009; Devyatkov et al., 2015). Desta forma, faz-se necessário o desenvolvimento de catalisadores em novas formas de agregação para serem usados em reatores contínuos como, por exemplo, pellets.

Para a preparação de catalisadores em forma de pellet, faz-se necessário a utilização de um agente aglomerante/ligante, de forma que seja possível moldar o catalisador. Na ausência do aglomerante, não seria possível dar o formato desejado, já que o pó de óxido de nióbio iria se desfazer facilmente. Além disso, é desejável que o aglomerante seja quimicamente inerte e estável, para que não haja interferência na reação química (Choudhary et al., 1999). Dos agentes aglomerantes, os inorgânicos promovem maior resistência mecânica ao pellet, no entanto podem levar à formação de sólidos com menor tamanho de poro. Já os orgânicos promovem uma melhor moldagem, mas enfraquecem a estrutura do catalisador. Além disso, há a necessidade de que os aglomerantes sejam evaporados ao fim da fabricação do pellet (De Jong, 2009). Portanto, esse trabalho tem como objetivo estudar a formação de pellets de pentóxido de nióbio $\left(\mathrm{Nb}_{2} \mathrm{O}_{5}\right)$, empregando álcool polivinílico (PVA) como agente aglomerante.

\section{METODOLOGIA EXPERIMENTAL}

Para preparar os pellets, foram necessárias algumas operações unitárias, dentre elas: preparação da pasta úmida, moldagem (por extrusão) e tratamento térmico dos pellets, conforme mostrado na Figura 1.

Figura 1 - Fluxograma de etapa de preparo dos pellets

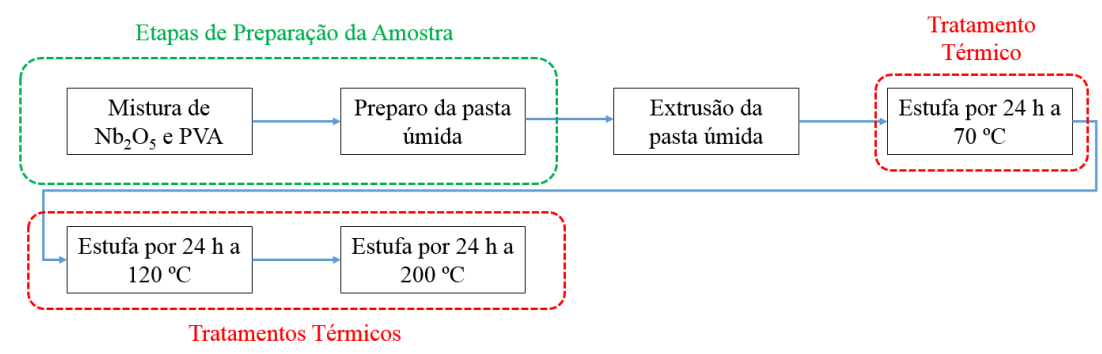




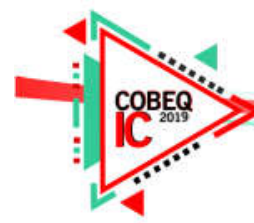

\subsection{Preparação e Extrusão do pellet de pentóxido de nióbio $\left(\mathrm{Nb}_{2} \mathrm{O}_{5}\right)$}

Inicialmente foi preparada uma pasta úmida, através da mistura de óxido de nióbio hidratado (vindo da CBMM marca AD/334) e PVA (da Acemis Artesanatos) na proporção de $10 \%$ e $15 \%$ em massa do agente aglomerante, de acordo com os trabalhos de Kawamura (2014). Nessa mistura foi gotejada água destilada com uma pipeta Pasteur até que fosse atingida uma proporção de óxido de nióbio e água de aproximadamente $1: 1(\mathrm{~g} / \mathrm{g})$, conforme mostrado nas Tabelas 1 e 2. Esse teor de água permitiu que o pó pudesse atingir a textura de uma pasta modelável e que seja possível moldar o pellet via extrusão.

Tabela 1 - Quantidade de água, agente aglomerante e óxido de nióbio usados na preparação dos pellets com $10 \%$ de PVA em massa

\begin{tabular}{|c|c|c|}
\hline Massa $\mathrm{Nb}_{2} \mathrm{O}_{5}(\mathrm{~g})$ & Massa PVA $(\mathrm{g})$ & Massa Água $(\mathrm{g})$ \\
\hline \hline 5,0018 & 0,4997 & 5,1489 \\
\hline \hline Razão PVA/ $\mathrm{Nb}_{2} \mathrm{O}_{5}$ & Razão Água/ $\mathrm{Nb}_{2} \mathrm{O}_{5}$ & Razão $\mathrm{Nb}_{2} \mathrm{O}_{5} /$ (Água +PVA) \\
\hline \hline 0,0999 & 1,0294 & 0,8855 \\
\hline
\end{tabular}

Tabela 2 - Quantidade de água, agente aglomerante e óxido de nióbio usados na preparação dos pellets com $15 \%$ de PVA em massa

\begin{tabular}{|c|c|c|}
\hline Massa $\mathrm{Nb}_{2} \mathrm{O}_{5}(\mathrm{~g})$ & Massa PVA $(\mathrm{g})$ & Massa Água $(\mathrm{g})$ \\
\hline \hline 4,9997 & 0,7507 & 4,9149 \\
\hline \hline Razão PVA/ $/ \mathrm{Nb}_{2} \mathrm{O}_{5}$ & Razão Água/ $\mathrm{Nb}_{2} \mathrm{O}_{5}$ & Razão $\mathrm{Nb}_{2} \mathrm{O}_{5} /$ (Água +PVA) \\
\hline \hline 0,1501 & 0,9830 & 0,8547 \\
\hline
\end{tabular}

A extrusão da pasta úmida foi feita verticalmente por um plastômero da marca $\operatorname{DSM}^{\circledR}$ modelo MI-3, como indicado na Figura 2. Então, foram obtidos os pellets úmidos no formato cilíndrico com um comprimento de cerca de $1 \mathrm{~cm}$. Posteriormente à extrusão, os pellets foram submetidos a tratamentos térmicos.

Figura 2 - Plastômero utilizado para a extrusão dos pellets a $25^{\circ} \mathrm{C}$ e $1 \mathrm{~atm}$

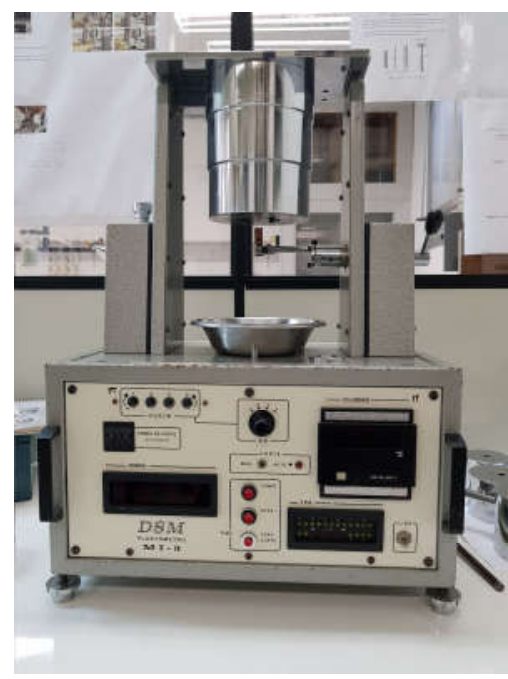




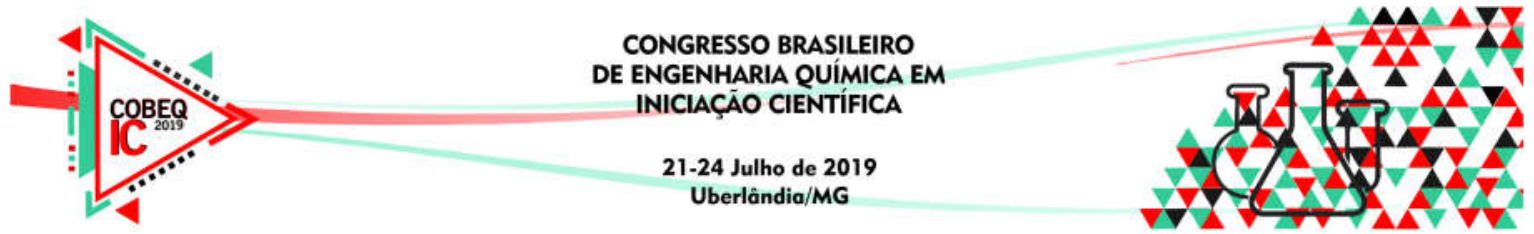

\subsection{Tratamento térmico dos pellets de pentóxido de nióbio $\left(\mathrm{Nb}_{2} \mathrm{O}_{5}\right)$}

Os pellets foram submetidos a uma sequência de etapas para tratamento térmico, no qual foram secos em uma estufa a $70{ }^{\circ} \mathrm{C}$ por $24 \mathrm{~h}, 120{ }^{\circ} \mathrm{C}$ por $24 \mathrm{~h}$, e por fim a $200{ }^{\circ} \mathrm{C}$ por mais $24 \mathrm{~h}$. Ressalta-se que a temperatura de tratamento térmico não pode exceder $400{ }^{\circ} \mathrm{C}$, visto que acima deste valor ocorre uma diminuição considerável de área superficial específica do óxido devido sua cristalização (Raba et al., 2016; Mejía et al., 2017).

\section{RESULTADOS E DISCUSSÃO}

As Figuras 3 e 4 mostram os resultados dos pellets com 10\% e 15\% de PVA após os tratamentos térmicos.

Figura 3 - Pellets com 10\% de PVA após o tratamento térmico em estufa: (a) $70{ }^{\circ} \mathrm{C}$ após 24 h, (b) $120^{\circ} \mathrm{C}$ após $24 \mathrm{~h}, \mathrm{e} \mathrm{(c)} 200^{\circ} \mathrm{C}$ após $24 \mathrm{~h}$

(a)

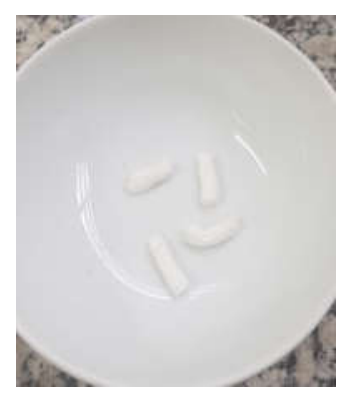

(b)

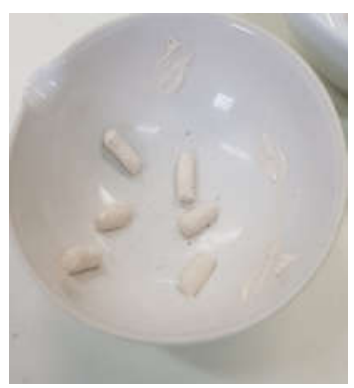

(c)

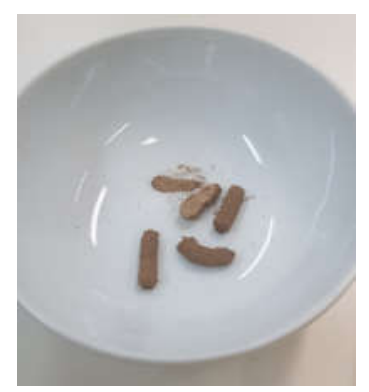

Ao observar a Figura 3, notou-se que após os tratamentos a 70 e $120^{\circ} \mathrm{C}$, não houve mudança de coloração dos cilindros. Contudo, após o tratamento a $200{ }^{\circ} \mathrm{C}$, os pellets mudaram de branco para marrom, o que pode ser um indício de que não houve evaporação total do PVA na partícula, mas sim o início de perda de massa. Esta hipótese foi formulada por análises termogravimétricas (TGA) presentes na literatura. Em seu trabalho, Betti (2016) reportou dois eventos de perda de massa em filmes de $100 \%$ de PVA: um entre 90 e $170{ }^{\circ} \mathrm{C}$ e outro entre 260 e $420{ }^{\circ} \mathrm{C}$. Segundo o autor, a primeira faixa de temperatura foi responsável pela perda de $3,1 \%$ da massa, ao passo que a segunda é referente à perda de $91,9 \%$ da massa do filme de PVA. Desta forma, traçando um paralelo com o presente estudo, sugere-se que a temperatura na terceira etapa do tratamento térmico deve ser aumentada para favorecer uma maior decomposição do agente aglomerante. Para além disso, notou-se uma intensa desagregação dos sólidos após a etapa final de tratamento térmico, sugerindo fragilidade.

Por sua vez, observou-se na Figura 4 que as partículas com 15\% de PVA obtiveram um formato mais uniforme e cilídrico, o que pode estar relacionado a maior porcentagem de agente aglomerante. Ao fim do tratamento térmico a $200{ }^{\circ} \mathrm{C}$, os pellets contendo $15 \%$ de PVA apresentaram intensa coloração escura, similar aos sólidos da Figura 3(c). Ressalta-se, contudo, que a resistência mecânica dos pellets com $15 \%$ de aglomerante foi superior aos que 


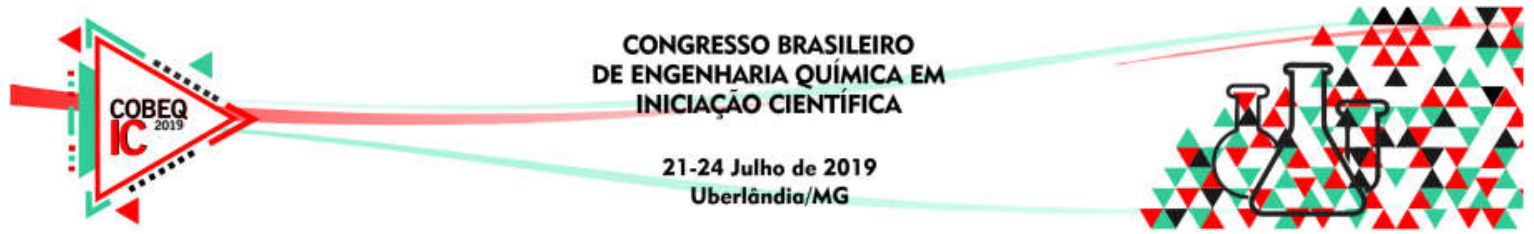

continham $10 \%$ de PVA, pois ao final do tratamento térmico, estes apresentaram apenas leve desagregação das partículas após o resfriamento de $200^{\circ} \mathrm{C}$ para a temperatura ambiente.

Figura 4 - Pellets com 15\% de PVA após o tratamento térmico em estufa: (a) $70{ }^{\circ} \mathrm{C}$ após 24 h, (b) $120^{\circ} \mathrm{C}$ após $24 \mathrm{~h}, \mathrm{e} \mathrm{(c)} 200^{\circ} \mathrm{C}$ após $24 \mathrm{~h}$

(a)

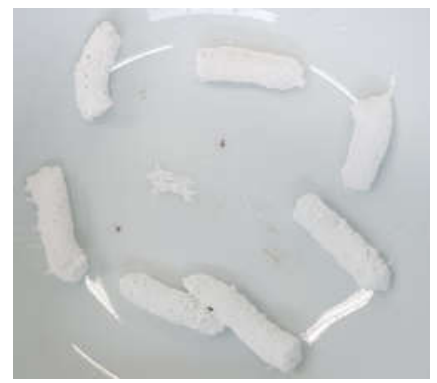

(b)

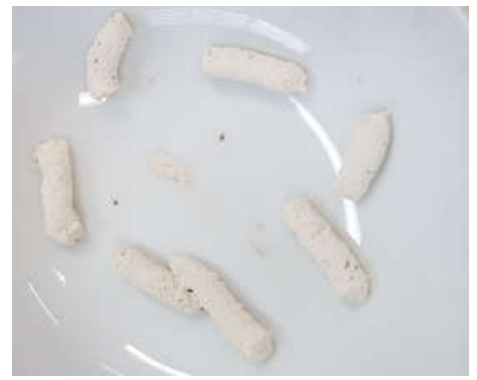

(c)

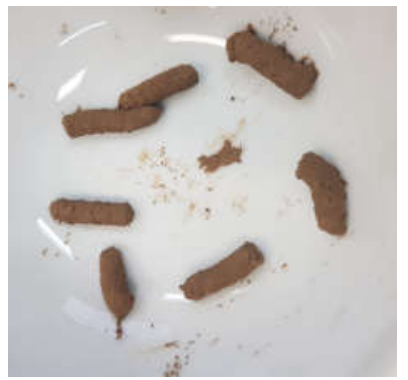

Por fim, sugere-se que a resistência mecânica possa ainda ser ajustada pelo método de moldagem da pasta úmida. Orrego-Romero et al. (2016) relataram o uso de prensagem com cerca de 1 tonelada métrica por 15 minutos na fabricação de pellets de carvão ativado. Desse modo, a inclusão da prensagem pode ser utilizada para futuros estudos na compactação.

\section{CONCLUSÕES}

Pellets cilíndricos de óxido de nióbio foram preparados usando-se extrusão em um plastômero com uso de álcool polivinílico (PVA) como um agente aglomerante. Após sucessivos tratamentos térmicos em estufa, houve mudança de cor nos cilindros bem como diminuição de resistência mecânica. Observou-se que o aumento no teor de PVA induziu efeitos positivos sobre a forma e resistência aparente das amostras. Deste modo, conclui-se que novos métodos de moldagem do pó bem como tratamentos térmicos deverão ser ajustados para conferir uma maior estabilidade ao pellet, para que este material seja apto a ser empregado em reatores de leito fixo.

\section{AGRADECIMENTOS}

O presente trabalho foi realizado com apoio da Coordenação de Aperfeiçoamento de Pessoal de Nível Superior - Brasil (CAPES) - Código de Financiamento 001. Além disso, os autores agradecem ao técnico da FEQ Fabricio Santos por ceder a utilização do plastômero.

\section{REFERÊNCIAS}

ALONSO, D.M.; BOND, J.Q.; DUMESIC, J.A. Catalytic Conversion of Biomass to Biofuels. Green Chemistry, v. 12, n. 9, 1493-1513, 2010.

ALVES, A.R.; COUTINHO, A.D.R. The Evolution of the Niobium Production in Brazil. Materials Research, v. 18, n. 1, 106-112, 2015. 


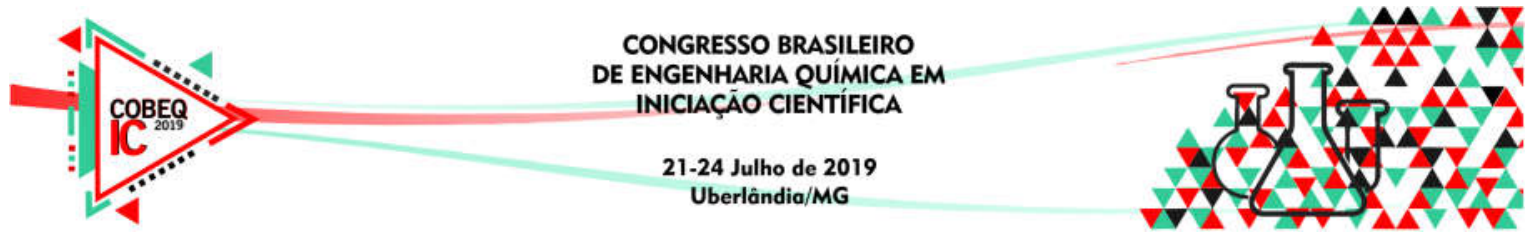

BETTI, N. A. Thermogravimetric Analysis on PVA / PVP Blend Under Air Atmosphere. Eng. \& Tech. Journal, v.34, n.13, 2433-2441, 2016.

CANHACI, S.J.; PEREZ, R.F.; BORGES, L.E.; FRAGA, M.A. Direct conversion of xylose to furfuryl alcohol on single organic-inorganic hybrid mesoporous silica-supported catalysts. Applied Catalysis B: Environmental, v. 207, 279-285, 2017.

CHOUDHARY, V.R.; SIVADINARAYANA, C. e MANTRI, K. Influence of Catalyst Binder on the Acidity and Activity/Selectivity of Ga/H-ZSM-5 Zeolite in Propane Aromatization. Journal of Chemical Sciences, v. 111, n. 5, 669-676, 1999.

DE JONG, K.P. Synthesis of Solid Catalysts. John Wiley \& Sons, 2009.

DEVYATKOV, S.; KUZICHKIN, N. e MURZIN, D.Y. On Comprehensive Understanding of Catalyst Shaping by Extrusion. Chimica Oggi-Chemistry Today, v. 33, 6, 2015.

GARCÍA-SANCHO, C.; AGIRREZABAL-TELLERIA, I.; GÜEMEZ, M.; MAIRELES TORRES, P. Dehydration of D-Xylose to Furfural using Different Supported Niobia catalysts. Applied Catalysis B: Environmental, v. 152, 1-10, 2014.

KAWAMURA, M. Preparação de Pellets de Catalisadores de Óxido de Alumínio. Trabalho de Conclusão de Curso. Universidade de Brasília, Brasília, 2014.

MARISCAL, R.; MAIRELES-TORRES, P.; OJEDA, M.; SÁDABA, I.; GRANADOS, M.L. Furfural: A Renewable and Versatile Platform Molecule for the Synthesis of Chemicals and Fuels. Energy \& Environmental Science, v. 9, n. 4, 1144-1189, 2016.

MEJÍA, C. H.; DEN OTTER, J. H.; WEBER, J. L.; DE JONG, K. P. Crystalline Niobia with Tailored Porosity as Support for Cobalt Catalysts for the Fischer-Tropsch Synthesis. Applied Catalysis A: General, v. 518, 143-149, 2017.

ORREGO-ROMERO, A. F.; ARBALÁEZ-PÉREZ, O. F.; BUSTAMANTE-LONDOÑO, F; HOLGUÍN, A. L. V. Pelletization of catalysts supported on activated carbon. A Case Study: clean synthesis of dimethyl carbonate from methanol and $\mathrm{CO}_{2}$. Revista Facultad de Ingeniería, n. 78, 38-47, 2016.

PRADHAN, P; MAHAJANI, S. M.; ARORA, A. Production and utilization of fuel pellets from biomass: A review. Fuel Processing Technology, v. 181, 215-232, 2018.

RABA, A. M.; BAUTISTA-RUÍZ, J.; JOYA, M. R. Synthesis and Structural Properties of Niobium Pentoxide Powders: A Comparative Study of the Growth Process. Materials Research, v. 19, n.6, 1-7, 2016. 